2018-07-03

\title{
Design(ing) and the Placebo EffectA Productive Idea
}

\section{Drayson, HE::0000-0002-4631-406X}

http://hdl.handle.net/10026.1/10095

10.1162/desi_a_00494

Design Issues

Massachusetts Institute of Technology Press (MIT Press)

All content in PEARL is protected by copyright law. Author manuscripts are made available in accordance with publisher policies. Please cite only the published version using the details provided on the item record or document. In the absence of an open licence (e.g. Creative Commons), permissions for further reuse of content should be sought from the publisher or author. 
Dr Hannah Drayson

Transtechnology Research

Plymouth University

B321 Portland Square

Drake Circus

PL4 8AA

hannah.drayson@plymouth.ac.uk

This is the author's accepted manuscript. The final published version of this work (the version of record) is published by MIT Press in Design Issues available at: http://www.mitpressjournals.org/loi/desi This work is made available online in accordance with the publisher's policies. Please refer to any applicable terms of use of the publisher. Please do not cite without author's permission.

\section{Design(ing) and the placebo effect; a productive idea.}

A placebo effect is the measurable beneficial healing effect that results from the context and meaning of a medical treatment rather than its content. While orthodox biomedicine has sometimes struggled to reconcile the paradox of seemingly inert medicines producing healing effects, in the placebo studies literature, a number of scholars have proposed that alternative paradigms for understanding perception, such as affordance, motor-intentionality, and enaction, can reconcile the apparent paradigm conflict.

These models are by no means incompatible with design theory, and are in fact both embedded within and enriched by a number of design sub-disciplines such as user experience (UX) design. This paper will show that understandings of placebo responsiveness, and the effects of meaning and symbol on the body, can be identified explicitly or implicitly in existing design and allied practices; industrial design, graphic and information design, marketing and branding, architecture.

While the placebo effect is perhaps not a problem in design, the wider cultural influence of the idea of placebo and what it means impacts on the contexts in which design's products are encountered. Observing the influence of placebo effects confirms the importance of - and one approach to articulating and exploring an audience's expectations and understanding of artefacts of meaning and culture. By talking about some of the ways in which the placebo effect has been mobilized, in the context of contemporary mid-Atlantic medical and scientific culture, this paper seeks to give a sense of the entangled ontological and epistemological frames that carry influence between disciplines and practices, in 
particular the health sciences and the arts. The placebo effect, as it becomes an increasingly influential concept, seems poised to influence how the meaningful aspects of design, its affect

$\mathrm{s}$ and affordances, come to matter. This paper proposes that the idea of the placebo response might offer a tool that can influence how design products and practices are received and valued.

\section{The Placebo}

To give someone a 'placebo' is to give a sham medical treatment in a way that gives them the impression that they are receiving medicines that are 'real and effective'1. Placebo treatments may include inactive 'pure' materials such as sugar pills, or 'active' but ineffective treatments, such as below-dose antidepressants or sham surgery ${ }^{2}$. Well known tools in medical trials, they are used to control for the range of extraneous factors that cause improvement in subjects ${ }^{3}$. While the beneficial effects of giving placebos as treatments has been known in medicine for a long time ${ }^{4}$ the practice is still considered somewhat dubious by patients and physicians alike 5 . Despite this, recent studies suggest that giving ineffective treatments to calm, placate, or even heal patients remains extremely common in general practice in the UK and US ${ }^{6}$. In the 1950s, the implication that giving placebo had healing effects began to receive an increasing amount of attention as a thorny problem for evidence-based medicine, demanding more a much more rigorous approach to medical trials ${ }^{7}$. In recent years, in a general shift away from mainly considering placebo

\footnotetext{
${ }^{1}$ Fabrizio Benedetti, Placebo Effects: Understanding the Mechanisms in Health and Disease, (Oxford: Oxford University Press. 2008), 34-35.

2 Bruce, J. Moseley, Kimberly O'Malley, Nancy J Petersen, Terri J Menke, Baruch A Brody, David H Kuykendall, John C Hollingsworth, Carol M Ashton, and Nelda P Wray. "A Controlled Trial of Arthroscopic Surgery for Osteoarthritis of the Knee.” New England Journal of Medicine 347, no. 2 (July 2002): 81-88.

${ }^{3}$ Franklin G Miller and David L Rosenstein. "The Nature and Power of the Placebo Effect." Journal of Clinical Epidemiology 59 (2006), 332.

4 Anton de Craen, Ted Kaptchuk, Jan G P Tijssen, and J Kleijnen. "Placebos and Placebo Effects in Medicine: Historical Overview." Journal of the Royal Society of Medicine 92 (1999): 511-15.

${ }^{5}$ Felicity L Bishop, Lizzi Aizlewood, and Alison E M Adams. "When and Why Placebo-Prescribing Is Acceptable and Unacceptable: a Focus Group Study of Patients' Views." PLoS ONE 9, no. 7 (2014).

${ }^{6}$ A 2013 survey of UK general practitioners, 1\% used pure and 77\% used impure placebos more than once a week in primary care practice., Jeremy Howick, Felicity L Bishop, Carl Heneghan, Jane Wolstenholme, Sarah Stevens, Richard Hobbs, and George Lewith. "Placebo Use in the United Kingdom: Results from a National Survey of Primary Care Practitioners.” Edited by Laxmaiah Manchikanti. PLoS ONE 8, no. 3 (March 20, 2013): e58247-6. These mirror similar findings in the U.S. Jon C Tilburt, Ezekiel J Emanuel, Ted J Kaptchuk, Farr A Curlin, and Franklin G Miller. "Prescribing 'Placebo Treatments': Results of National Survey of US Internists and Rheumatologists." Bmj 337, no. 23 (October 2008): a1938-38.

Also Margrit Fassler, Karin Meissner, Antonius Schneider, Klaus Linde (2010) Frequency and circumstances of placebo use in clinical practice - a systematic review of empirical studies. BMC Med 8: 15.

7 Ted Kaptchuk has argued that Henry Beecher's paper The Powerful Placebo influentially overstated the problem of placebo in medical trails, and inadvertently led to placebo being adopted as evidence for psychosomatic healing and
} 
effects as a risk to evidence-based research, an increasing number of researchers are exploring the potential of placebo effects in medical treatment. Proposals include extending pain medication doses by substituting with placebo tablets ${ }^{8}$, enhancing therapeutic encounters through psychological means ${ }^{9}$ or increasing adherence by changing the appearance of medicines. ${ }^{10}$

Placebo effects offer an important figure in the medical humanities for they expose the epistemological workings of the medical and psychological sciences ${ }^{11}$. The methodology of placebo-controlled medical trials separates all possible influences on healing from the treatments being tested and because of the way in which placebos are so often described as 'inert' medicine, placebo effects seem to become responses to nothing. Some have argued therefore that it makes more sense to talk about the placebo response, a move which shifts the discussion to focus on how the body-perceiver responds to medical contexts and meanings. ${ }^{12}$ Anthropologist Daniel Moerman has pointed out that while placebo effects are by definition limited to the realm of the medical, we should consider the interplay between meaning, symbol and biology in wider cultural contexts where other phenomena evidence what he calls the 'meaning

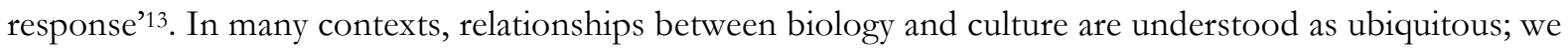
are rarely surprised for example if "we cry when we see a sad movie". ${ }^{14}$ However the discourse around medical testing, and certain interpretations of 'placebo' as deception and placebo treatments as 'inert'

alternative medicine. Ted J Kaptchuk, "Powerful Placebo: the Dark Side of the Randomised Controlled Trial." The Lancet 351 (1998): 1722-25.

Henry K Beecher, "The Powerful Placebo." Journal of the American Medical Association 159, no. 17 (December 24, 1955): 1602-6.

${ }^{8}$ Luana Colloca, Paul Enck and David DeGrazia. "Relieving Pain Using Dose-Extending Placebos." Pain 157, no. 8 (August 2016): 1590-98.

9 Marco Annoni and Franklin G Miller. "Placebo Effects and the Ethics of Therapeutic Communication: a Pragmatic Perspective.." Kennedy Institute of Ethics Journal 26, no. 1 (March 2016): 79-103. Also - Jim Sliwinski, and Gary R Elkins. "Enhancing Placebo Effects: Insights From Social Psychology.." American Journal of Clinical Hypnosis 55, no. 3 (January 2013): 236-48.

${ }^{10}$ Leander Steinkopf, "Enhancing Drug Compliance and the Placebo Effect by Raising Subjective Expectations." Medical Hypotheses 79, no. 5 (November 1, 2012): 698-700.

${ }^{11}$ Anne Harrington, "Seeing the Placebo Effect: Historical Legacies and Present Opportunities." and Daniel Moerman, "Explanatory Mechanisms for Placebo Effects: Cultural Influences and the Meaning Response." In The Science of the Placebo, edited by Arthur Kleinman, John Kusek, Linda Engel, and Harry Guess, (BMJ Books, 2002). ${ }^{12}$ Fabrizio Benedetti, "Placebo and the New Physiology of the Doctor-Patient Relationship." Physiological Reviews 93, no. 3 (2013).

${ }^{13}$ Moerman, "Explanatory Mechanisms", 77.

${ }^{14}$ Daniel Moerman, Meaning, Medicine and the "Placebo Effect," (Cambridge: Cambridge University Press, 2002), 5. While it might seem a commonplace that people cry at movies, it is neither universal, and nor does the apparent ubiquity of crying at sad movies explain how or why we do it. 
might be both symptom and reinforcement of the separation of cultural realms from those of the medical.

The earliest use of sham treatments in a medical trial is generally held to be the 1784 Franklin Commission which investigated Franz Anton Mesmer's claims regarding Animal Magnetism, in prerevolutionary France. Detractors and celebrants alike cite the Mesmer commission as a key historic moment in enlightenment medicine ${ }^{15}$. The goal of the enquiry was centered on testing Mesmer's claims that the cause of the healing effects experienced by his patients was that of an objective physical force, 'animal magnetism', a 'universal fluid'. ${ }^{16}$ Of the many experiments within the trial, some used deceptive measures. Patients were blindfolded and subjected to mesmeric passes, to which they responded at random, if at all ${ }^{17}$. Other patients were persuaded that the 'magnetical operation' was being performed upon them from behind a closed door, or while they were blindfolded, resulting in the same marked and recognizable responses in patients. ${ }^{18}$ The commission concluded that Mesmeric crises were produced by the actions of 'compression [pressing on the body], imagination, and to imitation', the socially learned behaviours of mesmerism. ${ }^{19}$ As a medical practice they dismissed it as dangerous to patients because the convulsions of mesemeric 'crises' had the potential to cause injury.

Isabelle Stengers has argued that this episode marked a point at which the role of the sciences shifted and 'scientists took on the role of guardians of an infantile public'. ${ }^{20}$ She points out that the imagination was a known component of medical practices like Mesmerism. It should, and according to their report, did not surprise the commissioners who set the terms of engagement such that Mesmerism could not fail but to be dismissed as a frippery. Tangled up with a dispute over who got to say what counted toward rationality and materiality were other forces, intensified by the political turmoil of pre-revolutionary France. In its

\footnotetext{
15 Steven Jay Lynn and Scott Lilienfeld. "A Critique of the Franklin Commission Report: Hypnosis, Belief and Suggestion" 50, no. 4 (October 2002): 369-86.

16 Mark A Best, Duncan Neuhauser, Lee Slavin. "Evaluating Mesmerism, Paris, 1784: the Controversy Over the Blinded Placebo Controlled Trials Has Not Stopped..” Quality \& Safety in Health Care 12, no. 3 (June 2003): 232-33.

${ }^{17}$ Henry Perkins, Animal Magnetism: Report of Dr. Franklin and other commisssioners, charged by the Kind of

France with the examination of the Animal Magnetism as practiced at Paris. Philadelphia: Chestnut Street, 1837: 24.

18 Perkins, Animal Magetism, 30.

19 Perkins, Animal Magetism, 44.

${ }^{20}$ Isabelle Stengers, “Diderot's Egg: Divorcing Materialism From Eliminativism.” Radical Philosophy 144 (2007), 12.
} 
growing popularity, Mesmerism had become associated with revolutionary groups, ${ }^{21}$ not least because,

paradoxically, while animal magnetism might sound supernatural to the contemporary ear, it was

Mesmer's attempt to embrace a materialist paradigm. As Stengers points out; 'Mesmer's magnetic fluid

was taken as a concrete affirmation of human equality, because it put into relation any humans, whatever their class'. ${ }^{22}$ The result: that the movement interfered both with royalist (and spiritual) hierarchies and the relationship of scientific medical authority to an apparently irrational and easily misled public.

\section{Expectancy, affordances and affect}

The question of what gets to be included within the purview of scientific medicine and what is bracketed remains associated with contemporary discussions of the placebo effect. Leading placebo researcher in the neurosciences Fabrizio Benedetti has cautioned that potential awareness of the discourse might increase public vulnerability to deceptions and quackery ${ }^{23}$. However legitimizing placebo or meaning effects may have more than epistemological implications.

The last two decades have seen the formation of an interdisciplinary field of placebo studies. Advocates from neuroscience and pharmacology have called for 'neuro-bio-behavioural'24 approaches to understanding placebo effects and have begun the project of untangling what have been for some time

\footnotetext{
${ }^{21}$ This was not limited to France, the influence of Mesmerism was arguably an influence in the 1791 Haitian slave revolution, to the extent that it prompted an 'anti-mesmerism' commission in St. Domingue that sought to maintain colonial power. See Kieran, M Murphy. "The Occult Atlantic: Franklin, Mesmer and the Haitian Roots of Modernity." In The Haitian Revolution and the Early United States, edited by Elizabeth Maddock Dillon and Michael J Drexler. (Pennsylvania: University of Pennsylvania Press, 2016), 149-153.

22 Stengers, Diderot's Egg, 12.

While Mesmer was discredited mesmeric practices persisted partly through the influence of his disciplines. Mesmerism (or at least something similar) later re-emerged in the use of hypnosis; in neurology in Saltpetriere and medicine in Nancy and influenced Freud's development of psychoanalytic techniques. In contrast with the commissioners' dismissal of the imagination, Mesmer's contemporaries were impressed by its effects. In 1800, Englishman John Haygarth's undertook experiments with his patients to explore the true value of 'metallic tractors' - instruments associated with 'perkinsonism' an off-shoot of mesmerism - pieces of metal that had been mesmerized, and could be used to produce healing effects. Haygarth reproduced the 'tractors' with pieces of wood and treated his patients with them, finding the sham treatment to have dramatic effects. He reported his endeavor in a treatise titled Of the Imagination, as a Cause and as a Cure of Disorders of the Body.

John Haygarth, Of the Imagination, as a Cause and as a Cure of Disorders of the Body; Exemplified by Fictitious Tractors, and Epidemical Convulsions (New Edition, with Additional Remarks), Bath; Published by R. Crutwell, 1800.

William Snow Miller. "Elisha Perkins and His Metallic Tractors." The Yale Journal of Biology and Medicine 8, no. 1 (October 1, 1935): 41-57.

23 Benedetti, Placebo, 1238.

${ }^{24}$ Manfred Schedlowski, Paul Enck, Winfried Rief, and Ulrike Bingel. "Neuro-Bio-Behavioral Mechanisms of Placebo and Nocebo Responses: Implications for Clinical Trials and Clinical Practice.” Pharmacological Reviews 67, no. 3 (2015): 697-730. 698.
} 
loosely referred to as 'nonspecific' mechanisms, predominantly by linking them to brain functions such as the release of certain neurotransmitters and hormones, mediating immune function through conditioned responses, or through psychological factors such as stress and relaxation. While there have been many experimental advances in the understanding and range of mechanisms that are now held to be conduits for information to travel from the realm of the meaningful to that of the physiological, it remains the case that these explanations tend to be held to fit predominantly with two main paradigms, conditioning and expectancy ${ }^{25}$.

Conditioned responses are non-cognitive and automatic. ${ }^{26}$ Some seemingly impressive placebo responses have been experimentally induced in research exploring the modulation of the immune systems of nonhuman animals such as experimental rats, as well human subjects ${ }^{27}$. In experiments of this type, a 'learned immune response'28 is produced by pairing an unconditioned stimuli such as a flavoured syrup containing saccharine with an immune suppressing drug. When the saccharine is later given alone, it produces the same immunosuppressant effects as the drug, without the 'active' content. ${ }^{29}$ Expectancy effects, on the other hand, result from the manipulations of conscious expectation. In the case of placebo effects this would be the positive expectation of healing associated with the medical encounter, context or placebo treatment. ${ }^{30}$ Expectations may be learnt from previous experience, or picked up from social cues or other sources.

Efforts to analyse these two leading views, conditioning and expectancy, quickly show problems. The two accounts appear to interact - for example when conditioned responses are mediated by conscious

\footnotetext{
${ }^{25}$ Schedlowski et al. Neuro-Bio-Behavioural Mechanisms, 699.

${ }^{26}$ A familiar example would be a taste-aversion that a person develops after eating or drinking something that later makes them sick, in some cases the stimuli, for example a crab sandwich, may be unconnected to the later illness, for example a virus. Despite this it is quite common for people - and animals - to develop taste aversions to previously 'unconditioned stimuli', becoming nauseous at the taste - or even mention - of crab sandwiches. 27 Benedetti, Placebo Effects, 1228.

${ }^{28}$ Manfred Schedlowski and Gustavo Pacheco-López. "The Learned Immune Response: Pavlov and Beyond." Brain, Behavior, and Immunity 24, no. 2 (2010): 176-85.

${ }^{29}$ Ader, R, and N Cohen. "Conditioning of the Immune Response." The Netherlands Journal of Medicine 39, no. 3 (October 1991): 263-73.

30 Steve Stewart-Williams, and John Podd. "The Placebo Effect: Dissolving the Expectancy Versus Conditioning Debate.” 130, no. 2 (2004): 324-40. 328.
} 
expectations. ${ }^{31}$ Insufficient alone, as Oron Frenkel points out, these two explanatory models are dogged by the models informing the medical trials which produce them, that perform and reinforce the tradition of 'separation between mental contents such as beliefs or expectations, and physiology'.32 Considering placebo effects as either conditioned (bodily and unconscious) or the result of cognitive expectations based on knowledge (conscious or available to consciousness) continues this tendency, failing to address the way in which the discourse constructs placebo effects as impossibilities. However some have suggested that what is needed is an alternative theory of perception, and that enactivist or existential phenomenological approaches provide an alternative. Frenkel argues that placebo effects might be better understood as the results of the perceived affordances of medical treatment. He suggests an interpretation of James Gibson's concept of perceptual affordance ${ }^{33}$ through Maurice Merleau-Ponty's existential phenomenology and suggests that placebo responses could be regarded as 'motor intentional'. Activities and objects associated with healing have bodily affordances. Giulio Ongaro and Dave Ward have continued this line of thinking. They argue that the apparent issues are resolved if we situate placebo in an 'enactivist' account;

[...] for the enactivist, the parts of an organism, the organism itself, and the environment with which the organism interacts emerge simultaneously from a shared dynamic tangle of processes. It is thus essential to living organisms that they create and sustain their constituent parts and processes, and that their doing so involves a reciprocal causal relationship with their environment. ${ }^{34}$

In the enactivist model, cognition is manifested by the environment and physical properties of the organism. By proposing we adopt a way of thinking that does not separate one from the other, Frenkel, and Ongaro and Ward clarify that the issue is not a lack of mechanism, but a pervasive habit of categorizing knowledge and experience as separate from the physiological body.

\section{Placebo as design deception}

The long association of placebo with sham has meant that both placebo and placebo effect have become

\footnotetext{
31 Stewart-Williams and Podd, Placebo Effect, 335.

32 Oron Frenkel, "A Phenomenology of the 'Placebo Effect': Taking Meaning From the Mind to the Body." Journal of Medicine and Philosophy 33 (2008), 73.

${ }^{33}$ James Gibson, The Ecological Approach to Visual Perception, New York and Hove: Taylor and Francis, 1986. 127-143.

34 Giulio Ongaro and Dave Ward, “An Enactive Account of Placebo Effects.” Biology \& Philosophy, April 12, 2017, 1-27. 9 .
} 
part of the vernacular, and are sometimes used to indicate deceptive design tactics, or misconceptions on the part of users. When a New York Times article reported that a large number of the pedestrian crossings in Manhattan had non-functioning buttons, the article's author used the metaphor to describe the perceived effects; “[...] some buttons we regularly rely on to get results are mere artifices — placebos that promote an illusion of control but that in reality do not work". ${ }^{35}$ Michael Beirut's article in Design Observer made a similar point about non-functional 'close' buttons in elevators, and the signs outside his family home that warned would-be burglars about the (non-functioning) security alarms. ${ }^{36}$

In conceptual design projects, the term placebo has been used loosely to indicate 'less defined objects that could invoke desire or imagination'37 or directly misleading prototype technologies. Anthony Dunne and Fiona Raby's Placebo Project included a non-functioning 'electro—draught excluder', a device that supposedly mopped up electro-magnetic radiation in the home. ${ }^{38}$ Like medical placebos, 'sham' design interventions invoke responses that offer a way to probe the space of imagination around technological forms and objects. The objects in Dunne and Raby's experiments were intended to offer 'psychological comfort' as well as open dialogues with participants about the way in which the technologies were incorporated into personal space and narratives. One participant reported feeling as if the device was modifying her physical experience of the electro-magnetic radiation in her home. ${ }^{39}$

\section{Form and medical efficacy}

Some discussions in design have directly invoked a notion of a placebo response as a healing effect, for example hospital architecture..$^{40}$ In the design of medicines and their packaging, intentionally invoking placebo effects requires care; it raises many side issues, in particular ethics and patient safety, but also trademarking and intellectual property. The placebo literature shows a range of factors that correlate the

\footnotetext{
35 Christopher Mele, "Pushing That Crosswalk Button May Make You Feel Better, but ...." The New York Times, 2016.

36 Michael Bierut, “Information Design and the Placebo Effect.” Design Observer. Accessed 1.07.2017. http://designobserver.com/feature/information-design-and-the-placebo-effect/1927.

${ }^{37}$ Koefoed Hansen, Lone, and Susan Kozel. "Embodied Imagination: a Hybrid Method of Designing for Intimacy." Digital Creativity 18, no. 4 (December 2007): 207-20. 210.

38 Anthony Dunne and Fiona Raby, Design Noir: the Secret Life of Electronic Objects, (Basel: Birkhäuser, 2001), 75.

${ }^{39}$ Dunne and Raby, Design Noir, 89-91,

${ }^{40}$ Charles Jencks, The Maggie's Centers and the Arbitectural Placebo. Online essay. Accessed 29.06.2017 http://www.charlesjencks.com/\#!articles-by-charles-jencks
} 
appearance and form of medical treatments with enhanced efficacy; the shape and colour of tablets and packaging ${ }^{41}$, methods of administering treatment - injection versus tablet, ${ }^{42}$ dosage, adherence to treatment regimen ${ }^{43}$, information on leaflets and in marketing, therapeutic rituals and rationales. ${ }^{44} \mathrm{But}$ when designing for the delivery of potentially dangerous pharmacological materials, it might appear rather imprudent (both dangerous and unethical) to design for the extension of imaginative engagement, or worse, deception, at the potential cost of patient safety, usability, and treatment adherence. 45

\section{Direct-to-consumer advertising and the 'irreducible materiality' of the trademark.}

In the United States, where direct-to-consumer advertising (DTCA) of prescription drugs is permitted, the complexity of these interactions is particularly visible. Legal wrangles over 'lookalike' generic drugs essentially copies of prescription drugs whose patents have lapsed - have raised the question of how design is might be biologically 'functional'. Generic drugs are manufactured after larger companies' drug patents have expired - the appearance, colour and shape of tablets and capsules of brand-name drugs are sometimes aped by smaller companies with the intention of offering more competitive prices (and taking some of the market share) by providing what are effectively identical products. ${ }^{46}$ While drug patents can only be held for a specific time, the 'trade dress' - the style in which a product is 'dressed' for sale - such as the iconic black and red of the Mars Bar or the curved shape of the Coca-Cola bottle - can be protected indefinitely. The criteria for what is considered trade dress include that infringements would confuse consumers, and that the dress must be 'non-functional' - only referring to the appearance of the product, not its 'function' or active content. Jeremy Greene ${ }^{47}$ cites a number of legal cases in which elements that might be thought to be trade dress were ruled to be a functional and therapeutic aspect of the medicine.

\footnotetext{
${ }^{41}$ Anton J M de Craen, Pieter J Roos, Leonard A de Vries, and Jos Kleijnen. "Effect of Colour of Drugs: Systematic Review of Perceived Effect of Drugs and of Their Effectiveness..” Bmj 313, no. 7072 (1996): 1624-26.

42 Ted J Kaptchuk, P Goldman, D A Stone, and W B Stason. "Do Medical Devices Have Enhanced Placebo Effects?” Journal of Clinical Epidemiology 53, no. 8 (August 2000): 786-92.

43 For a general review see Moerman, Meaning, 77-94)

${ }_{44}$ An analysis of approaches is offered by Leander Steinkopf, "Enhancing Drug Compliance and the Placebo Effect by Raising Subjective Expectations." Medical Hypotheses 79, no. 5 (November 1, 2012): 698-700.

45 This is reflected by UK guidelines for the design of medical packaging, which discuss legibility, and the risks inconsistencies in the display of information. Design for Patient Safety, National Patient Safety Agency (NPSA), 2006. Available online http://www.nrls.npsa.nhs.uk/EasySiteWeb/getresource.axd?AssetID=63052

${ }^{46}$ Jeremy A Greene and Aaron S Kesselheim. "Why Do the Same Drugs Look Different? Pills, Trade Dress, and Public Health." New England Journal of Medicine 365, no. 1 (2011): 83-89.

47 Jeremy A Greene "The Materiality of the Brand: Form, Function, and the Pharmaceutical Trademark." History and Technology 29, no. 2 (2013): 210-26. 214-22.
} 
He cites an early precedent, the 1959 court case in which Norwich, the manufacturers of Pepto-Bismol, attempted to protect their rights to the pink liquid form it was sold in. In a reflection of studies of the time of color-related placebo effects in gastric physiology and psychosomatic medicine, ${ }^{48}$ the court ruled that the 'soothing' pink colour was a 'functional' and 'therapeutic' feature of the product, and therefore could not be protected as trade dress.

Greene suggests that relation between presentation and effect seem to be more quickly and easily accepted in contemporary legal contexts. He gives the case of the ADHD medication 'Adderall', with its distinctive colour and shape schemes - orange and blue tablets and capsules - that correlate to its effects (speed of release) and dosages. A court ruled that another manufacturer should be able to copy the appearance of the tablets, because their appearance was so distinctive that changing to a generic drug with a different appearance could cause problems for patients. First, it might confuse or mislead about the contents or dosage of the tablets/capsules, but also fail to produce the placebo responses that long adherence to the Adderall branded drug regime would have built up, therefore reducing the effect of the drug. ${ }^{49}$ A mixture of somewhat nonspecific factors, the beneficial 'function' of the colour and shape includes safety and adherence as well as the psychological and physiological effects associated with the placebo effect. Colour and form might seem relatively basic considerations in the presentation of medicine, but this discussion reveals what Greene calls the 'irreducible materiality' of trademarks and trade dress. As he puts it "[p]harmaceuticals are powerful symbols of reductionism in biomedical therapeutics, but as examination of the lookalike drug controversy reminds us, there is an irreducible materiality to any therapeutics, even within the molecularized and commodified realm of pharmaceuticals". ${ }^{50}$ Greene's examples reflect a mixture of forces at work that reflect changes in attitudes and influence regarding both the idea of placebo as well as ethical and commercial forces. The popular interpretation of scientific medicine is mediated by the legal system and hardening of probably opportunistic legal precedent, the complexity and pragmatics of the (supposed) life-worlds of patients, and the consumer-focused nature of the US pharmaceutical industry.

\footnotetext{
48 Greene, Materiality, 214.

${ }^{49}$ Greene, Materiality, 220.

${ }^{50}$ Greene, Materiality, 220
} 
In addition to trade dress, marketing itself has offered a focus for its potential to enhance the effects of prescription drugs through placebo responses. In a 2013 paper titled Placebogenic Potential is no reason to favour pharmaceutical advertising, Paul Biegler responds to the arguments of a 2006 Plos 1 special issue on pharmaceutical advertising ${ }^{51}$. The opening editorial puts forward the argument that if commercials have conditioning and expectancy effects, they may increase patient response to pharmaceuticals. Therefore it is morally permissible, and perhaps even required, to expose potential drug users to the relevant commercials. ${ }^{52}$ In his critique, Biegler accepts that; 'the placebo response furthers medically desirable outcomes and is, therefore, a warranted treatment component under the guiding principle of beneficence', but opposes drugs marketing because the manipulations of response and expectation have the potential to skew 'understandings of drug safety and efficacy'. ${ }^{53}$ His concern; that marketing can cause users of these drugs to develop 'unjustified beliefs' regarding their efficacy, preventing them from making 'autonomous' choices about their drug regimen. ${ }^{54}$

In his 1980 essay Advertising, the Magic System, Raymond Williams' gives an elegant potted history of marketing and its growth in early print media. Advertising is in a sense, the official art of modern capitalist society ${ }^{55}$. He notes that the earliest controversies around advertising related to the selling of 'patent medicines' and that by the 1930s, the leading expenditure of advertising revenue as a percentage of sales was in proprietary medicines. ${ }^{56}$ We might argue that it is the nature of medical charlatanry to exploit the desire to live long lives and to avoid pain and discomfort, but Williams' Marxist analysis also points to the capitalist logic of exploiting all possible potential in a system of production. Here the productive excess, the 'magic' at work is the bodily affect afforded by advertising. As is clear from the

\footnotetext{
51 The editors of the issue give the background to the debate here, two of them proposing that there could be beneficial placebo effects to advertising, and that it should be regulated rather than banned. Elizabeth A Almasi, Randall S Stafford, Richard L Kravitz, and Peter R Mansfield. "What Are the Public Health Effects of Direct-toConsumer Drug Advertising?.” PLOS Medicine 3, no. 3 (2006): e145.

52 Paul Biegler, "Placebogenic Potential Is No Reason to Favour Pharmaceutical Advertising." Journal of Business Ethics 123, no. 1 (2014): 145-55. 146.

53 Biegler, Placebogenic Potential, 145.

${ }^{54}$ Biegler, Placebogenic Potential, 145.

55 Raymond Williams, “Advertising - the Magic System (1960/1969)." in Jim McGuigan (ed) Raymond Williams on Culture \& Society: Essential Writings, 57-84, (London: SAGE Publications Ltd, 2014), 334.

56 Williams, Advertising, 332.
} 
discussions of DTCA and trade dress, this potential, and its connection to placebo effects has not been lost on marketers who have looked a subjective and performance related responses to the branding of products..$^{57}$ In one experiment, the differing effect of recognizable versus unrecognizable brands of isotonic sports drinks on blood pressure regulation were measured. The study showed that blood pressure measures reflected the physiological and 'subconscious' effects on participants' bodies exerted by brand expectations. ${ }^{58}$ Augmenting and extending the perceived affordances of a product, branding enhances and extends it effects through the action of the perceiver, increasing the value of the product. Imaginative skill and reception, qualities not only found within the consumer, but afforded by their engagement with the material properties of the world, are mobilized to productive effect. It is no surprise that this excess is identified and mobilized within the practices of marketing, just as general practitioners make use of placebos in the day-to-day surgeries, in these sites it is results rather than epistemic constructs that rule.

\section{Why talk, about placebo? Stories about relations.}

While placebo responses, and the mechanisms that enable them, remain an ongoing concern in the medical sciences, in design the apparent problems caused by interaction between cognition and physiology seem to present less of a paradox. In design theory, the influence of affordance theory and allied approaches that consider cognition as bodily, active and situated, mean that interactions between expectation and physiology should not seem mysterious. If this is the case, why talk about the placebo effect, or placebo response?

One suggestion is that the placebo effect's apparent weirdness is useful, primarily because it shows the fault lines between orders of thing and where the authority lies to decide what is talked about and what isn't. As Anne Harrington describes in her history of mind-body medicine, The Cure Witbin, the narratives of mind-body interactions which sound 'a bit like biography, a bit like biology, a little like mechanism, a

${ }^{57}$ Shiv, B, Z Carmon, and Dan Ariely. "Placebo Effects of Marketing Actions: Consumers May Get What They Pay for." Journal of Marketing Research XLII (2005): 383-93.

${ }^{58}$ Carlos Alberto Alves, Evandro Luiz Lopes, and José Mauro da Costa Hernandez. "It Makes Me Feel So Good: an Experimental Study of the Placebo Effect Generated by Brands." Journal of International Consumer Marketing, (May 9, 2017): 1-16. 
little like meaning'59 offer a storied world that can 'knit together domains of experience that we struggle otherwise to relate' ${ }^{\prime} 0$. As a cultural object, the placebo effect posits interactions between such categories as emotions, ideas and thoughts, stress, behavior, genes, organ systems, immune system and the brain. Generally speaking, the popular science press have used the term placebo synonymously with mistaken interpretations; just placebo, as with just imagination, rather than genuine effects, or even experiences. ${ }^{61}$ However, placebo effect narratives make for compelling journalism, ${ }^{62}$ and it is worth contemplating the potential effects of what these stories suggest as they circulate and gather acceptance. The validation of the placebo effect within popular thought may not only change the effectiveness of placebos for medical treatments, -a possibility picked up by Steve Silberman in a 2009 article for Wired magazine ${ }^{63}$. It may also impact the affordances of meaning; how the products of design - images, aesthetics, architectures might change or influence somatic or affective experience and produce knock-on health effects. Placebo effects, or at least stories about them, if not directly suggestive, still preparing people to experience design in certain ways. The possibility of instrumentalising the idea of the placebo effect relies on the plausibility of the narratives that explain it, ${ }^{64}$ whether used to convince a marketing team, a jury, or a patient.

There is another side to the suggestion that affect might be increased. Conversely, a lack of cultural expectations regarding the effects of meaning on the body might also, or already have, changed how medical rituals influence healing by reducing them. It may have eliminated, or at least reduced some of the affective experiences associated with cultural and aesthetic products. This is not to say that these things do not afford these experiences themselves, but we must be able to perceive them as offering the potential for particular experience, a process which would naturally be historically contingent and malleable, and potentially to be intervened on. ${ }^{65}$ As Stengers has pointed out, the tendency to 'the decided

\footnotetext{
${ }^{59}$ Anne Harrington, The Cure Within: a History of Mind-Body Medicine, (W. W. Norton \& Company, 2009$), 251$.

${ }^{60}$ Harrington, Cure, 255.

${ }^{61}$ De Craen et al. Placebos.

62 Jo Marchant's articles on immune conditioning, and 'open label' placebo are good examples. Marchant, "You Can Train Your Body Into Thinking It's Had Medicine, Mosaic," (2016), 1-12. and "Placebos: Honest Fakery." Nature, (2016).

${ }^{63}$ Steve Silberman, "Placebos Are Getting More Effective. Drugmakers Are Desperate to Know Why." Wired. Accessed June 30, 2017. https://www.wired.com/2009/08/ff-placebo-effect/.

64 Steinkopf, Enhancing.

${ }^{65}$ This is an observation not lost in clinical hypnosis, (which also makes use of expectancy as a model) where researchers who developed a training system (The Carlton Skills Package) to dispel myths about the nature and practice of hypnotism extended the hypnotic abilities of those who used it. Approaches to managing and forming
} 
elimination of whatever cannot be connected with a rather vague version of what physicists claim to be reality', enables for the sciences the 'conquering of new territories by disqualifying everything that cannot be aligned with what they call "materialism" or "naturalism"”. ${ }^{66}$ In the contemporary telling of the Franklin commission's invention of scientific medicine, and the narrow readings of 'materialism', the imagination is collateral in a long-running dispute. ${ }^{67}$ At minimum, a discussion of placebo effects can operate to shift thinking. Architect Charles Jencks ${ }^{68}$ cites Daniel Moerman's ${ }^{69}$ work on the placebo effect as a powerful prompt that led him to rethink an accepted truth in architectural practice, that buildings could not be deterministically used to modify their inhabitants. Likewise, the legal and research questions raised in marketing regarding the potential mobilization of placebo effects through marketing, branding and drug design, are symptoms of possible shifts in attitude towards affect and causality. While the move to theoretical positions that champion accounts of immanence and affect neo- or vital- materialisms pervades the critical humanities, medical humanities and science and technology studies, the question remains of how this thinking may be mobilized through examples that can shift practice, or perhaps more accurately, our understanding of what is going on in practice, is an ongoing concern.

\section{Summary}

The ways of thinking about human perception and experience that inform a number of branches of design practice, such as affordance theory, are not in conflict with the evidence associated with placebo responses and meaning effects. However, 'placebo' remains somewhat synonymous with deception and illusion, and reviews of the historical discourses that shape contemporary of placebo effect suggest that dismissing or overlooking placebo effects may play to the disciplinary and cultural imperatives that are concerned with power and legitimacy. Placebo responses are, to an extent, occult within many design practices that contribute to or are associated with medicine. Examples of the manifestations of the

expectations are described in Green, Joseph P. 2010. "Beliefs About Hypnosis: Popular Beliefs, Misconceptions, and the Importance of Experience.” International Journal of Clinical and Experimental Hypnosis 51 (4): 369-81.

66 Stengers, Diderot's Egg, 8.

${ }^{67}$ Edward Reed's history charting the repression of vitalist thinking in the formation of psychology extends this discussion. Edward S Reed. From Soul to Mind, New Haven and London: Yale University Press, 2014.

${ }^{68}$ Jencks, Maggie's Centers.

${ }^{69}$ Moerman, Meaning. 
placebo effect in debates around the design of medical treatments suggests that the concept of placebo in the wider culture is both influential and worth attending to. While discussions around direct-to-consumer advertising and trade dress acknowledge the placebo effect, they also support the consequent idea that many aspects of design practice invoke affordances that have implications for healing and may, in the case of marketing, produce an affective excess. The placebo effect offers a complex example of how the discourses of medical science shape expectations for engagement with the products of design, and, as a consequence, may mediate the affective and somatic potential of cultural products. 